\title{
EL RÉGIMEN ECONÓMICO MATRIMONIAL EN EL REINO UNIDO
}

THE ECONOMIC MATRIMONIAL REGIME IN THE UNITED KINGDOM

\author{
Alfonso Ortega Giménez \\ Universidad Miguel Hernández, Elche. España/Spain \\ alfonso.ortega@umh.es
}

Recibido/Received: 14/04/2017

Modificado/Modified: 20/09/2017

Aceptado/Accepted: 10/10/2017

\section{RESUMEN}

El presente artículo trata de explicar el régimen económico matrimonial en el Reino Unido y sus diferencias con el régimen económico matrimonial español. Aborda la asignación judicial del patrimonio según el principio de equidad y sus diferencias y similitudes con el régimen económico legal de separación de bienes.

\section{PALABRAS CLAVE}

Régimen económico matrimonial; Common Law; cónyuges.

\section{SUMARIO}

1. Planteamiento: la familia jurídica del Common Law. 2. El régimen económico legal es el de separación de bienes. Asignación judicial del patrimonio según el principio de equidad. 3. Diferencias entre el régimen económico matrimonial británico y el régimen económico matrimonial español. 4. Conclusiones. Bibliografía.

\section{ABSTRACT}

The present paper tries to explain the economic matrimonial regime in the United Kingdom and its differences with the Spanish matrimonial economic regime. It addresses the judicial allocation of the estate according to the principle of equity and their differences and similarities with the legal economic regime of separation of property.

\section{KEYWORDS}

Economic matrimonial regime; Common Law; Spouses.

\section{CONTENTS}

1. Approach: the legal family of the Common Law. 2. The legal economic regime is that of the separation of property. Judicial allocation of the estate according to the principle of equity. 3 . Differences between the British matrimonial economic regime and the Spanish matrimonial economic regime. 4. Conclusions. References. 


\section{PLANTEAMIENTO: LA FAMILIA JURÍDICA DEL COMMON LAW}

Todos los intentos de sistematización comparativa actuales entienden que el Common Law es una de las grandes familias jurídicas. Aunque el Common Law abarca casi a una cuarta parte de los países del mundo, la familia jurídica se caracteriza por una increíble armonía en sus características esenciales.

A la familia jurídica del Common Law pertenecen todos los países que alguna vez en el pasado han sido (o todavía son en la actualidad) colonias de Inglaterra, por tanto, en particular, los países de la Commonwealth y los Estados Unidos (o dicho de manera sencilla, los países donde el inglés es la lengua oficial). El inglés como lengua oficial y el Common Law son dos fuerzas que han sobrevivido al desaparecido imperio británico, ambos elementos siguieron a los soldados británicos que llegaron como conquistadores y ambos han permanecido incluso después de haberse arriado para siempre la bandera del imperio.

Los países con Common Law determinan el derecho aplicable al régimen económico del matrimonio, en el caso de bienes muebles, de manera distinta según el domicilio respectivo de los cónyuges. Por lo que se refiere a los bienes inmuebles rige el derecho aplicable en el lugar respectivo (división del derecho patrimonial).

En este sentido no debe confundirse el concepto de domicilio (domicile) según el Common Law con el domicilio en el sentido del ordenamiento jurídico romanogermánico. La justificación de un nuevo domicile of choice no sólo presupone que objetivamente esté justificada la residencia (residence) en otro país, sino también la intención de permanecer allí de manera permanente y sin ánimo de volver (animus manendi et non revertendi).

En particular, el Derecho inglés y los ordenamientos jurídicos próximos a éste plantean unos elevados requisitos a la intención de permanecer en el nuevo país, de tal manera que el concepto de domicilio (domicile) según el derecho inglés se aproxima mucho al de nacionalidad (país de pertenencia).

\section{EL RÉGIMEN ECONÓMICO LEGAL ES EL DE SEPARACIÓN DE BIENES. ASIGNACIÓN JUDICIAL DEL PATRIMONIO SEGÚN EL PRINCIPIO DE EQUIDAD}

La separación de bienes es el "régimen legal" en prácticamente todos los países con Common Law. Según el Common Law, el matrimonio no tiene efecto alguno sobre la propiedad y la capacidad de disposición de los cónyuges. Por ello en el Common Law no se cita ni una sola vez el concepto de régimen económico del matrimonio. Sin embargo, en caso de divorcio, el tribunal puede asignar bienes de un cónyuge al otro cónyuge, aplicando el principio de equidad. Esto está regulado procesalmente como una facultad del juzgador (con frecuencia en una ley, Matrimonial Causes Act), pero no como una regla sustantiva para el régimen de bienes en el matrimonio. El juez puede aplicar su criterio tanto basándose en motivos de régimen económico como también en materia de alimentos. La ley regula ciertamente en muchos países las circunstancias a sopesar a la hora de aplicar este criterio pero no entra en detalles en cuanto al volumen de la transmisión.

De ahí que en muchas ocasiones la denominación habitual de "régimen económico" del Common Law, como separación de bienes, se entiende como demasiado limitada. Resulta 
más apropiado hablar de una separación de bienes con asignación judicial del patrimonio según el principio de equidad.

El porcentaje que vienen asignando los juzgados al cónyuge con menos ingresos o al cónyuge encargado de las tareas del hogar es hoy notablemente superior al de otros tiempos. Esto también puede dar lugar, sobre todo, a un reparto del patrimonio por la mitad, toda vez que los tribunales, partiendo ahora del principio de igualdad (equality), consideran compatible llevar la casa y la educación de los hijos con la actividad profesional.

Al contrario de lo que ocurre en la sociedad legal de gananciales, la asignación judicial del patrimonio puede abarcar también otros elementos patrimoniales que uno de los cónyuges haya aportado al matrimonio (en este sentido, incluso totalmente comparable con la plena comunidad de bienes).

Los regímenes económicos matrimoniales de las jurisdicciones continentales delimitan los derechos de propiedad de los cónyuges y proporcionan reglas claras de división de los bienes en caso de divorcio. El régimen económico matrimonial por defecto puede no ser el adecuado para todos los matrimonios (aunque probablemente lo sea para la gran mayoría), pero los sistemas jurídicos continentales otorgan prioridad a la seguridad jurídica sobre la equidad individual con respecto a la propiedad, otorgando a los otros efectos de la ruptura un tratamiento separado (mayoritariamente discrecional) a través del maintenance.

\section{DIFERENCIAS ENTRE EL RÉGIMEN ECONÓMICO MATRIMONIAL BRITÁNICO Y EL RÉGIMEN ECONÓMICO MATRIMONIAL ESPAÑOL}

Uno de los aspectos más relevantes que los abogados deben analizar en los casos de divorcios transfronterizos es el régimen económico matrimonial (matrimonial property regime), es decir, las normas que regulan la propiedad de los bienes adquiridos durante el matrimonio (family assets). En España, el régimen económico matrimonial por defecto, es decir, si los esposos no pactan lo contrario, es el de comunidad de bienes, también denominado "sociedad de gananciales". Significa que todos los bienes adquiridos durante el matrimonio son de los dos cónyuges (spouses) a partes iguales, lo que debe ser tenido en cuenta a la hora de proceder al reparto de los bienes familiares. Algunos autores opinan que éste es también el régimen aplicable en Inglaterra y Gales, pero esta afirmación debe ser matizada, como haremos a continuación. Cataluña y Escocia, sin embargo, tienen por defecto el régimen de separación de bienes (separate property system) que, en sentido contrario al de comunidad, significa que los bienes adquiridos durante el matrimonio son propiedad privativa del cónyuge que los adquiere o pertenecen a los dos en proporción al dinero que cada uno ha aportado para su adquisición.

La principal dificultad a la que nos enfrentamos en estos casos es que, a diferencia de los sistemas basados en el Derecho civil como el nuestro, el Derecho inglés no cuenta con un régimen económico matrimonial como tal aplicable al matrimonio. En Inglaterra y Gales no existe una comunidad de bienes (community of property). La celebración del matrimonio no tiene efectos patrimoniales, es decir, el matrimonio per se no produce ningún efecto inmediato sobre los derechos de propiedad de los cónyuges. Sin embargo, en el momento del divorcio los tribunales disponen de una amplia libertad para distribuir los ingresos y los activos de los cónyuges con el fin de lograr un resultado justo. Para conseguir este resultado pueden dictar una gran variedad de órdenes o medidas judiciales 
conocidas como ancilliary relief dirigidas a obtener la liquidación de los efectos económicos del matrimonio.

Pero, esa libertad tiene una serie de limitaciones y pautas que orientan su aplicación que aparecen en la ley que regula los procesos de divorcio (Matrimonial Causes Act 1973). También la jurisprudencia (case law) de los tribunales ingleses ha matizado este tema señalando que el principio general a aplicar debe ser el de reparto igualitario de los bienes en caso de divorcio, es decir, como si existiera comunidad de bienes, salvo que exista causa suficiente para apartarse de ese principio. Así lo establecen sentencias como la del asunto Charman vs. Charman (2007), en el cual, un tribunal de apelación inglés declaró: "(...) entendemos que "el principio de reparto" significa que los bienes deben ser repartidos en proporciones iguales a no ser que exista una buena razón para apartarse de ese criterio (...)".

Lo anterior tiene como consecuencia que se aplique, a posteriori, un criterio parecido al de la comunidad de bienes española. Pero hay que tener presente la gran capacidad discrecional de la que el juez dispone para determinar el reparto de los bienes lo que, en la práctica, supone que será difícil predecir el resultado de una sentencia de divorcio en un caso concreto.

Si preguntamos a un abogado de familia inglés cuál es el régimen económico matrimonial que existe en Inglaterra y Gales, nos mirarán con franco desconcierto. ¿Por qué? Sencillamente porque Inglaterra y Gales están sujetos a la jurisdicción de derecho común y no existe ni Código Civil ni el concepto de régimen económico matrimonial.

Cuando dos personas heterosexuales contraen matrimonio, o dos personas del mismo sexo se inscriben como pareja de hecho (en Inglaterra el matrimonio homosexual no está permitido), todos los bienes que figuren a su nombre siguen siendo de su única titularidad. Cualquier obligación que tenga a su nombre sigue siendo de su cuenta exclusiva. Nada cambia en cuanto a la relación jurídica con terceros fuera de la pareja. Si el marido es demandado por deudas, la esposa no corre el riesgo de ver embargados sus bienes. Esto es, obviamente, en la medida en que ella pueda acreditar que los bienes son de su exclusiva propiedad. Por ejemplo, si la esposa tiene una casa a su nombre, ya sea adquirida antes o durante la vigencia del matrimonio, y sobre la cual el esposo no haya hecho ninguna contribución económica ni para su adquisición ni para su mejora, si el esposo tiene acreedores los bienes de la esposa siguen siendo de ella y no podrán embargarla.

Curiosamente, éste no fue siempre el criterio, pues cambió a partir de la promulgación de la Ley de Propiedad de 1925, cuya sección 37 dejó sentado que: "El marido y la mujer, a los efectos de adquisición de cualquier participación en propiedad, en virtud de una disposición ya hecha o que se llevara a efecto después de la entrada en vigor de esta Ley, serán tratados como dos personas distintas."

Por tanto, en Derecho inglés no se produce una confusión de patrimonios como consecuencia del matrimonio.

De ahí que exista el mito de que en Inglaterra tienen "separación de bienes", en relación con terceros, puesto que los cónyuges conservan su propio patrimonio durante toda la vigencia del matrimonio. Desde el punto de vista del abogado español, ésta es la pregunta más frecuente cuando las partes inician un procedimiento de divorcio y surge la cuestión de la aplicación del Derecho inglés. En este contexto, pensar que existe el régimen de "separación de bienes" no puede estar más lejos de la realidad.

En caso de divorcio o separación de la pareja de hecho debidamente inscrita, tanto los bienes como los ingresos se distribuyen, en Inglaterra y Gales, tomando en consideración lo establecido en la Sección 25 de la Ley de Procedimientos Matrimoniales de 1973. 
Dicha Sección 25 (1 y 2) de la Ley de Procedimientos Matrimoniales de 1973 establece una serie de factores que deben tenerse en cuenta:

“a) los ingresos, capacidad adquisitiva, propiedades y otros recursos financieros que cada una de las partes del matrimonio tuviera o pudiera adquirir previsiblemente en el futuro, incluyendo en el caso de capacidad adquisitiva, cualquier incremento en dicha capacidad que pudiera ser, en la opinión de los Tribunales, razonable esperar que una de las partes del matrimonio realizara;

b) las necesidades financieras, obligaciones y responsabilidades que cada uno de los miembros del matrimonio tenga o pueda tener en el futuro;

c) el nivel de vida disfrutado por la familia antes de la ruptura del matrimonio;

d) la edad de cada una de las partes al casarse y la duración del matrimonio;

e) cualquier incapacidad física o psíquica de cualquiera de los miembros del matrimonio;

f) las contribuciones hechas por cada una de las partes o las que pudiera hacer en el futuro para el bienestar de la familia, incluyendo cualquier contribución para el mantenimiento del hogar o el cuidado de la familia;

g) la conducta de cada una de las partes, si dicha conducta fuera en opinión del Tribunal injusto no considerar;

h) en el caso de procedimientos de divorcio o anulación del matrimonio, el valor para cada una de las partes del matrimonio de cualquier beneficio que, como consecuencia de la disolución del matrimonio, la parte perdiera la posibilidad de adquirir".

Además, los Tribunales ingleses tendrán en cuenta la jurisprudencia, en particular la reciente decisión de la Casa de los Lores en el caso Miller vs. Miller (2006) o, con anterioridad en el caso White vs. White (2000).

En el caso White se señaló que, a la hora de valorar los bienes matrimoniales, el Tribunal tiene derecho a tener en cuenta todos los bienes independientemente de su origen y a nombre de quién conste la posesión o el registro. No importa quién aportó qué al matrimonio ni cómo ni dónde se adquirieron los bienes posteriores, ya que el tribunal tiene pleno poder para incluir el valor de dichos bienes en su valoración global, así como a incluir bienes registrados a nombre de una sola de las partes.

El caso Miller fue dilucidado por la Casa de los Lores que es el más alto Tribunal del Reino Unido. En concreto, las partes deberán cumplimentar el denominado "Formulario E", y hacer una relación de todos sus bienes y derechos, ya sean adquiridos con anterioridad al matrimonio, durante la vigencia del mismo, o que esté previsto adquirir en un futuro (herencias, bonos, etc.). Todos estos bienes y derechos forman el llamado "saco matrimonial", cuyo contenido el Juzgado ha de distribuir entre las partes.

El principal factor a tener en cuenta en la mayoría de los casos son las necesidades de la familia más que las contribuciones de los cónyuges (que en la mayoría de los casos modestos será prácticamente irrelevante).

En el caso McFarlane vs. McFarlane (2006), relativo a las consecuencias económicas del divorcio, se identificó la necesidad, la compensación y el reparto (needs, compensation and sharing) como los tres elementos a tener en cuenta para resolver un caso con justicia. Esto es, hay una serie de factores que el tribunal debe tener en cuenta a la hora de tomar su determinación, incluyendo necesidades presentes y futuras, recursos, capacidad de generar ingresos, edad, duración del matrimonio y las contribuciones de cada cónyuge a la economía familiar.

No hay una remisión expresa a ningún régimen matrimonial ni a capitulaciones matrimoniales, aunque lo cierto es que la jurisprudencia inglesa está avanzando en este 
tema, y ya hay algún caso reciente como el de $Z$ y Z (2011) en relación a un régimen de "separación de bienes" francés pactado por los cónyuges, según el cual en Francia la esposa hubiera recibido el $15 \%$ del haber conyugal, mientras que en Inglaterra el Tribunal le otorgó un $40 \%$. Si no hubiera sido porque firmaron el pacto sobre el régimen económico matrimonial, hubiera recibido, con casi total seguridad, el 50\% del haber conyugal. En este caso, las partes eran muy ricas, y su patrimonio excedía con creces sus necesidades. El $40 \%$ de los bienes permitió que la esposa tuviese más que suficiente para vivir manteniendo un alto nivel de vida. En un asunto más modesto es muy dudoso que el hecho de que el matrimonio hubiera firmado unas capitulaciones fijando su régimen económico matrimonial tuviera efecto alguno en las medidas definitivas.

Las aportaciones de los cónyuges previas al matrimonio son meramente un factor a tener en cuenta. No están protegidas y, cuando existen necesidades, sobre todo necesidades de alojamiento, la realidad es que a los Tribunales ingleses no les importa la procedencia del bien, a excepción de matrimonios de muy corta duración.

Pongamos como ejemplo el caso del matrimonio de Paul McCartney con Heather Mills. A pesar de que ella no aportó nada al matrimonio y él era quien aportaba todos sus bienes al mismo, aun así la Sra. Mills recibió 25 millones de libras. Esta suma era para cubrir sus necesidades.

Los Tribunales ingleses no tienen ningún reparo en transmitir bienes de un cónyuge a otro o de una parte a otra, y ello incluye hasta las pensiones de jubilación. Un Tribunal inglés no tiene ningún problema en transmitir la titularidad de una propiedad recibida por herencia por una de las partes a la otra si lo considera necesario. El hecho de quién sea titular del bien es irrelevante a efectos prácticos.

Por tanto, si comparamos ambos ordenamientos en este punto, no pueden ser más dispares, pues en España siempre existe un régimen económico matrimonial, bien porque lo estipulen los cónyuges en capitulaciones matrimoniales o por disposición legal según su vecindad civil, con las limitaciones establecidas en el Código Civil. El Juez está obligado a respetar la titularidad de los bienes y la naturaleza de los mismos, privativa o ganancial, sin que pueda disponer de ellos según su criterio. De hecho, en España ni siquiera la distribución de los bienes matrimoniales se contempla en el procedimiento de divorcio, siendo éste un procedimiento distinto del de liquidación del haber conyugal. Así, desde el punto de vista del abogado español, el "régimen económico matrimonial inglés" se parece más a un régimen ganancial sui generis, que al régimen de separación de bienes cuando nos encontramos en un proceso de divorcio. Desde el punto de vista del abogado inglés, ¡no hay tal régimen matrimonial!

\section{CONCLUSIONES}

La posición de partida para la división del capital en un divorcio es la división de los bienes a partes iguales.

El Tribunal tiene amplios poderes que puede ejercer como resultado de una solicitud económica tras un procedimiento de divorcio, que incluya, p. ej., el pago de una pensión alimenticia, el pago de una cantidad global, la creación de un fondo fiduciario mediante el pago de una cantidad global para proporcionar pagos periódicos, el traspaso de propiedad o bienes o el uso de una propiedad.

No existe una fórmula fija utilizada por el Tribunal para presentar un cálculo simple con el fin de establecer una división justa y razonable de ingresos y bienes entre las partes, 
sobre la base de, entre otros, los ingresos y recursos disponibles de las partes, las posibles necesidades futuras de las partes, el nivel de vida antes de la separación, la edad de la pareja, la duración del matrimonio, las cualidades físicas y mentales de cada persona, la contribución el bienestar continuado de la familia, la conducta, o el cambio de la situación económica como resultado del divorcio o la separación.

En definitiva, en el Derecho inglés, en caso de divorcio, el Tribunal puede asignar bienes de un cónyuge al otro cónyuge, aplicando el principio de equidad. En el momento del divorcio los tribunales disponen de una amplia libertad para distribuir los ingresos y los activos de los cónyuges con el fin de lograr un resultado justo. El principio general a aplicar debe ser el de reparto igualitario de los bienes en caso de divorcio, esto es, los bienes deben ser repartidos en proporciones iguales a no ser que exista una buena razón para apartarse de ese criterio.

\title{
BIBLIOGRAFÍA
}

Abarca Junco, A.P. (1983) "Sobre los efectos o relaciones personales entre los cónyuges en DIPr.", REDI, pp. 43-60.

Amores Conradí, M.A. (1987) "Las relaciones entre cónyuges en el nuevo DIPr. de la familia: valores jurídicos y técnicas de reglamentación”, $A D C$, pp. 89-138.

Carrascosa González, J. (2000) Matrimonio y elección de Ley. Estudio de DIPr. Granada: Comares.

Diago Diago, M.P. (1999) Pactos o capitulaciones matrimoniales en Derecho internacional privado. Zaragoza: Colección El Justicia de Aragón.

Diago Diago, M.P. (2008) "La publicidad del régimen económico matrimonial y la protección de terceros en Derecho Internacional Privado español", BIMJ, 2067-2068: 2763-2787.

Fontanellas Morell, J.M. (2008) "Reflexiones sobre el apartado 3 del artículo 9 del Código Civil", en $\mathrm{M}^{\mathrm{a}} \mathrm{T}$. Areces Piñol. Estudios jurídicos sobre persona y familia. Granada: Comares, pp. 355-370.

Gómez Campelo, E. (2008) Los regímenes matrimoniales en Europa y su armonización. Madrid: Editorial Reus, S.A.

Rodríguez Pineau, E. (2002) Régimen económico matrimonial. Aspectos internacionales. Granada: Comares.

Simó Santonja, V.L. (1991) Regímenes matrimoniales. Legislación comparada. Pamplona: Aranzadi.

\section{Breve currículo:}

\begin{abstract}
Alfonso Ortega Giménez
Profesor Contratado Doctor de Derecho internacional privado y Vicedecano de Grado en Derecho de la Facultad de Ciencias Sociales y Jurídicas de la Universidad Miguel Hernández de Elche. Subdirector del Master en Comercio Internacional, Universidad de Alicante. Director del Master online en Internacionalización de la empresa, EIS. Consultor Derecho internacional privado, Universitat Oberta de Catalunya, 2008/2009. Consejero académico PELLICER \& HEREDIA ABOGADOS. Director del Observatorio provincial de Inmigración de Alicante. Director del Observatorio de Inmigración de la ciudad de Elche, 2011/2015, Vocal del Observatorio Valenciano de la Inmigración. Autor, coautor, y/o director o coordinador, en más de 80 libros.
\end{abstract}

